\title{
Effect of Physiologic Hyperinsulinemia on Skeletal Muscle Protein Synthesis and Breakdown in Man
}

\author{
Robert A. Gelfand and Eugene J. Barrett \\ Department of Internal Medicine and the General Clinical Research Center, Yale University School of Medicine, \\ New Haven, Connecticut 06510
}

\begin{abstract}
Although insulin stimulates protein synthesis and inhibits protein breakdown in skeletal muscle in vitro, the actual contribution of these actions to its anabolic effects in man remains unknown. Using the forearm perfusion method together with systemic infusion of $\mathrm{L}-\left[\right.$ ring $\left.-2,6-{ }^{3} \mathrm{H}\right]$ phenylalanine and $\mathrm{L}-\left[1-{ }^{14} \mathrm{C}\right.$ leucine, we measured steady state amino acid exchange kinetics across muscle in seven normal males before and in response to a 2 -h intraarterial infusion of insulin. Postabsorptively, the muscle disposal $\left(R_{d}\right)$ of phenylalanine $(43 \pm 5 \mathrm{nmol} / \mathrm{min}$ per $100 \mathrm{ml}$ forearm) and leucine (113 \pm 13$)$ was exceeded by the concomitant muscle production $\left(R_{a}\right)$ of these amino acids $(57 \pm 5$ and $126 \pm 9 \mathrm{nmol} /$ min per $\mathrm{dl}$, respectively), resulting in their net release from the forearm ( $-14 \pm 4$ and $-13 \pm 5 \mathrm{nmol} / \mathrm{min}$ per $\mathrm{dl}$, respectively). In response to forearm hyperinsulinemia $(124 \pm 11 \mu \mathrm{U} / \mathrm{ml})$, the net balance of phenylalanine and leucine became positive $(9 \pm 3$ and $61 \pm 8 \mathrm{nmol} / \mathrm{min}$ per $\mathrm{dl}$, respectively $(P<0.005 \mathrm{vs}$. basal). Despite the marked increase in net balance, the tissue $\boldsymbol{R}_{\mathrm{d}}$ for both phenylalanine (42 \pm 2$)$ and leucine (124 \pm 9$)$ was unchanged from baseline, while $R_{\mathrm{a}}$ was markedly suppressed (to $33 \pm 5$ and $63 \pm 9$ $\mathrm{nmol} / \mathrm{min}$ per $\mathrm{dl}$, respectively, $P<0.01$ ). Since phenylalanine is not metabolized in muscle (i.e., its only fates are incorporation into or release from protein) these results strongly suggest that in normal man, physiologic elevations in insulin promote net muscle protein anabolism primarily by inhibiting protein breakdown, rather than by stimulating protein synthesis.
\end{abstract}

\section{Introduction}

In vitro studies have firmly established the ability of insulin to stimulate protein synthesis and inhibit protein degradation in skeletal muscle (1-9). In man, insulin has been shown to promote a more positive net balance of amino acids across muscle (10), but whether this anabolic effect is mediated primarily by an alteration in protein synthesis, breakdown, or both remains unknown. In the present study we addressed this question using a new isotopic technique for assessing protein synthesis and breakdown in human forearm muscle.

Address reprint requests to Dr. Gelfand, Department of Internal Medicine, Fitkin 103, Yale University School of Medicine, 333 Cedar Street, New Haven, CT 06510.

Received for publication 15 October 1986 and in revised form 27 February 1987.

J. Clin. Invest.

(c) The American Society for Clinical Investigation, Inc.

$0021-9738 / 87 / 07 / 0001 / 06 \$ 2.00$

Volume 80, July 1987, 1-6

\section{Methods}

Subjects and experimental design. Seven healthy adult male volunteers age 18-29 yr were studied after a 10-12-h overnight fast. All weighed within 15\% of ideal body weight (Metropolitan Life Insurance Tables, 1983). Skeletal muscle amino acid exchange kinetics were measured using a combination of the conventional forearm muscle balance method (11) with the systemic infusion of radiolabeled phenylalanine and leucine. Catheters were introduced percutaneously into the brachial artery and into an ipsilateral deep forearm vein (retrograde) draining muscle (12). Through a contralateral arm vein, subjects received a 4-h primed-continuous infusion of $\mathrm{L}-\left[\right.$ ring- $\left.2,6-{ }^{3} \mathrm{H}\right]$ phenylalanine $(\sim 32 \mu \mathrm{Ci}, 0.64 \mu \mathrm{Ci} /$ $\min )\left(8.1 \pm 0.4 \times 10^{5} \mathrm{dpm} / \mathrm{min}\right)$ and $\mathrm{L}-\left[1-{ }^{14} \mathrm{C}\right]$ leucine $(\sim 9 \mu \mathrm{Ci}, 0.14 \mu \mathrm{Ci} /$ min) $\left(2.3 \pm 0.2 \times 10^{5} \mathrm{dpm} / \mathrm{min}\right)$. After. a 2 -h basal tracer equilibration period, during which patency of the arterial catheter was maintained by a slow infusion of normal saline $(0.3 \mathrm{ml} / \mathrm{min})$, insulin (diluted in a solution of normal saline and albumin) was infused directly into the brachial artery at $0.05 \mathrm{mU} / \mathrm{kg}$ per min for $2 \mathrm{~h}$, using the same volume infusion rate. Arterial and venous blood samples were obtained at $-30,-15$, and 0 min during the basal state, and at 80,100 , and 120 min during the insulin infusion, when all measurements exhibited steady state conditions. A pediatric sphygmomanometer cuff was inflated about the wrist to 200 $\mathrm{mmHg}$ for $3 \mathrm{~min}$ before and during each sampling interval to exclude blood flow to the hand. Forearm blood flow (13) was measured at each sampling interval from the dilution of indocyanine green dye (ICG) ${ }^{1}$ infused intraarterially for $5 \mathrm{~min}$. Forearm volume was determined by water displacement.

Each subject gave informed, written consent before participating in the study, which was approved by the Human Investigations Committee of Yale University.

Analytical methods. Blood glucose concentration was measured by the glucose oxidase method, and plasma insulin concentration was measured with a double antibody radioimmunoassay (14). The concentration of ICG dye in infusate and plasma were measured spectrophotometrically at $810 \mathrm{~nm}$. Blood phenylalanine and leucine concentrations were measured in sulfesalicylic acid extracts of blood using an automated ion exchange chromatographic technique (D-500, Dionex, Sunnyvale, CA). For the determination of $\mathrm{L}-\left[\right.$ ring- $\left.2,6-{ }^{3} \mathrm{H}\right]$ phenylalanine and $\mathrm{L}-[1-$ ${ }^{14} \mathrm{C}$ leucine radioactivity, duplicate aliquots of each sulfosalicylic acid extract and tracer infusate were placed on a Dowex $50 \mathrm{~W}$ cation exchange column (Bio-Rad Laboratories, Richmond, CA); radioactivity was quantitated in the eluted amino acid fraction using a dual channel liquid scintillation counter with external standard correction (Packard Instruments, Downers Grove, IL). Recovery of amino acid standards from the Dowex column averaged $97 \pm 2 \%$. More than $98 \%$ of the ${ }^{14} \mathrm{C}$-radioactivity and $95 \%$ of the ${ }^{3} \mathrm{H}$-radioactivity in circulating amino acids were in the leucine and phenylalanine peaks, respectively, after separation by ion exchange chromatography.

Calculations. The net forearm balances of glucose and amino acids were calculated as

Net balance $=([A]-[V]) \times F$

1. Abbreviations used in this paper: ICG, indocyanine green dye; KIC, alpha-ketoisocaproate; $R_{\mathrm{a}}$, rate of production; $R_{\mathrm{d}}$, rate of disposal; $S A_{\mathrm{a}}$, arterial specific activity; $S A_{\mathrm{v}}$, venous specific activity. 
where $A$ and $V$ are the arterial and venous blood concentrations, respectively, and $F$ is the forearm blood flow.

The net muscle balance of phenylalanine and leucine represents the difference between two simultaneously ongoing processes, namely, the rate of tissue amino acid disposal $\left(R_{\mathrm{d}}\right)$, and the rate of tissue amino acid production $\left(R_{\mathrm{a}}\right)$; that is,

Net balance $=R_{\mathrm{d}}-R_{\mathrm{a}}$

The tissue disposal of blood-borne phenylalanine or leucine can be calculated from the measured fractional extraction $(E)$ of its tracer as

$R_{\mathrm{d}}=E \times[A] \times F$

where $E$ is the arteriovenous difference in tracer radioactivity divided by arterial tracer radioactivity (all in $\mathrm{dpm} / \mathrm{ml}$ ). Muscle production of new (unlabeled) amino acid can then be calculated from Eq. 1-3:

$R_{\mathrm{a}}=E \times[A] \times F-([A]-[V]) \times F$,

which reduces to the expression:

$R_{\mathrm{a}}=F \times[V] \times\left(1-S A_{\mathrm{v}} / S A_{\mathrm{a}}\right)$

where $S A_{\mathrm{a}}$ and $S A_{\mathrm{v}}$ denote the specific activity (dpm/nmol) of phenylalanine or leucine in artery and vein, respectively. Expressing Eq. 4 conceptually, the measured dilution across the tissue of tracer specific activity is used to calculate the contribution to the total venous amino acid efflux $(F \times[V])$ of unlabeled amino acid produced by the tissue.

These calculations define the kinetics of amino acid exchange between forearm muscle and the circulating blood. By resolving the net balance measurement into its component rates of disposal and release, the technique can elucidate the kinetic processes underlying an alteration in the observed net tissue balance. For phenylalanine, which is neither synthesized nor metabolized in muscle $(2,15-17)$, the measured rate of disappearance of tracer across the forearm at steady state should reflect its incorporation into protein, while tissue release of new, unlabeled phenylalanine should reflect its release from the breakdown of tissue protein.

The whole body flux rates (micromoles per minute) of circulating phenylalanine and leucine were calculated from the rate of tracer infusion (disintegrations per minute per minute) divided by the steady state amino acid specific activities in arterial blood (disintegrations per minute per micromole).

Data presentation and statistical analyses. Statistical comparisons between the basal and insulin infusion periods, and between arterial and venous measurements, were performed using analysis of variance with repeated measures (CRISP Statistical Package, Crunch Software, San Francisco, CA). All data are presented as mean \pm SEM. The basal and insulin infusion periods were summarized by averaging the three steady state determinations in each subject for each period.

\section{Results}

Basal forearm muscle amino acid kinetics. In the overnight fasted state deep venous blood concentrations of phenylalanine and leucine were significantly higher than arterial (Table I, Fig. 1), indicating net release of these amino acids from muscle. In contrast, tracer radioactivity concentrations were significantly higher in artery than in deep vein, indicating a substantial disappearance across muscle of arterial phenylalanine and leucine, which was exceeded by the concomitant tissue release into blood of unlabeled amino acids. This release of unlabeled amino acid from forearm muscle is reflected in the significant dilution of specific activity which was observed between artery and vein (Table I, Fig. 1). For phenylalanine (net balance $=-14 \pm 4 \mathrm{nmol} / \mathrm{min}$ per $100 \mathrm{ml}$ of forearm), disposal $\left(R_{\mathrm{d}}\right)$ averaged $43 \pm 5$, while release $\left(R_{\mathrm{a}}\right)$ averaged $57 \pm 5 \mathrm{nmol} / \mathrm{min}$ per $100 \mathrm{ml}$; for leucine (net balance $=-13 \pm 5)$, the corresponding rates were $113 \pm 12$ and $126 \pm 9$ $\mathrm{nmol} / \mathrm{min}$ per $100 \mathrm{ml}$, respectively (Fig. 2). The whole body flux rates for circulating phenylalanine and leucine were $41 \pm 3$ and $99 \pm 6 \mu \mathrm{mol} / \mathrm{min}$, respectively, values that agree well with previous steady state measurements in postabsorptive man $(18,19)$.

Response to local hyperinsulinemia. Infusion of insulin into the brachial artery raised forearm deep venous insulin concentrations (basal, $6 \pm 1 \mu \mathrm{U} / \mathrm{ml}$ ) to high physiologic levels (124 \pm 11 $\mu \mathrm{U} / \mathrm{ml}, P<0.001)$ for $2 \mathrm{~h}$. Systemic insulin concentrations measured in a contralateral arm vein showed no detectable increase during the study $(6 \pm 1 \mu \mathrm{U} / \mathrm{ml})$. Glucose disposal in the insulin-perfused forearm rose fourfold $(1.15 \pm 0.13$ to $4.67 \pm 0.67$ $\mu \mathrm{mol} / \mathrm{min}$ per $100 \mathrm{ml}, P<0.005$ ); arterial (systemic) blood glucose concentrations showed a slight decline during the study (4.6 $\pm 0.1 \mathrm{mM}$, basal, to $4.3 \pm 0.1 \mathrm{mM}, P<0.05$ ). Forearm blood flow showed a small, but significant $25 \%$ increase during insulin infusion, $(3.2 \pm 0.2$ to $4.0 \pm 0.4 \mathrm{ml} / \mathrm{min}$ per $\mathrm{dl}, P<0.05)$, consistent

Table I. Summary of Arterial and Deep Venous Concentrations of Phenylalanine, $L-\left[\right.$ ring- $\left.2,6-{ }^{3} H\right]$ Phenylalanine, Leucine, and $L-\left[1-{ }^{14} \mathrm{C}\right]$ Leucine, in the Basal State $(-30$ to $0 \mathrm{~min}$ ) and in Response to Physiologic Hyperinsulinemia (80 to $120 \mathrm{~min})$

\begin{tabular}{|c|c|c|c|c|c|c|}
\hline & \multicolumn{3}{|c|}{ Phenylalanine } & \multicolumn{3}{|l|}{ Leucine } \\
\hline & Basal & Insulin & $P^{*}$ & Basal & Insulin & $P^{*}$ \\
\hline \multicolumn{7}{|c|}{ Concentration ( $\mu$ mol/liter) } \\
\hline Artery & $48 \pm 1$ & $49 \pm 1$ & NS & $110 \pm 3$ & $108 \pm 2$ & NS \\
\hline Vein & $53 \pm 2$ & $46 \pm 2$ & $<0.01$ & $114 \pm 3$ & $92 \pm 3$ & $<0.005$ \\
\hline$P(A$ vs. $\mathrm{V})$ & $<0.02$ & $<0.07$ & & $<0.02$ & $<0.001$ & \\
\hline \multicolumn{7}{|c|}{ Radioactivity $(\mathrm{dpm} / \mathrm{ml})$} \\
\hline Artery & $964 \pm 85$ & $1051 \pm 77$ & NS & $258 \pm 28$ & $269 \pm 24$ & NS \\
\hline Vein & $688 \pm 62$ & $809 \pm 59$ & $<0.001$ & $172 \pm 19$ & $189 \pm 16$ & $<0.02$ \\
\hline$P(A$ vs. V $)$ & $<0.001$ & $<0.001$ & & $<0.001$ & $<0.001$ & \\
\hline \multicolumn{7}{|c|}{ Specific activity $($ dpm/nmol $)$} \\
\hline Artery & $20 \pm 2$ & $22 \pm 2$ & NS & $2.4 \pm 0.3$ & $2.6 \pm 0.2$ & NS \\
\hline Vein & $13 \pm 1$ & $18 \pm 2$ & $<0.001$ & $1.5 \pm 0.2$ & $2.1 \pm 0.2$ & $<0.001$ \\
\hline$P(A$ vs. V) & $<0.001$ & $<0.001$ & & $<0.001$ & $<0.001$ & \\
\hline
\end{tabular}

* Basal vs. insulin. 

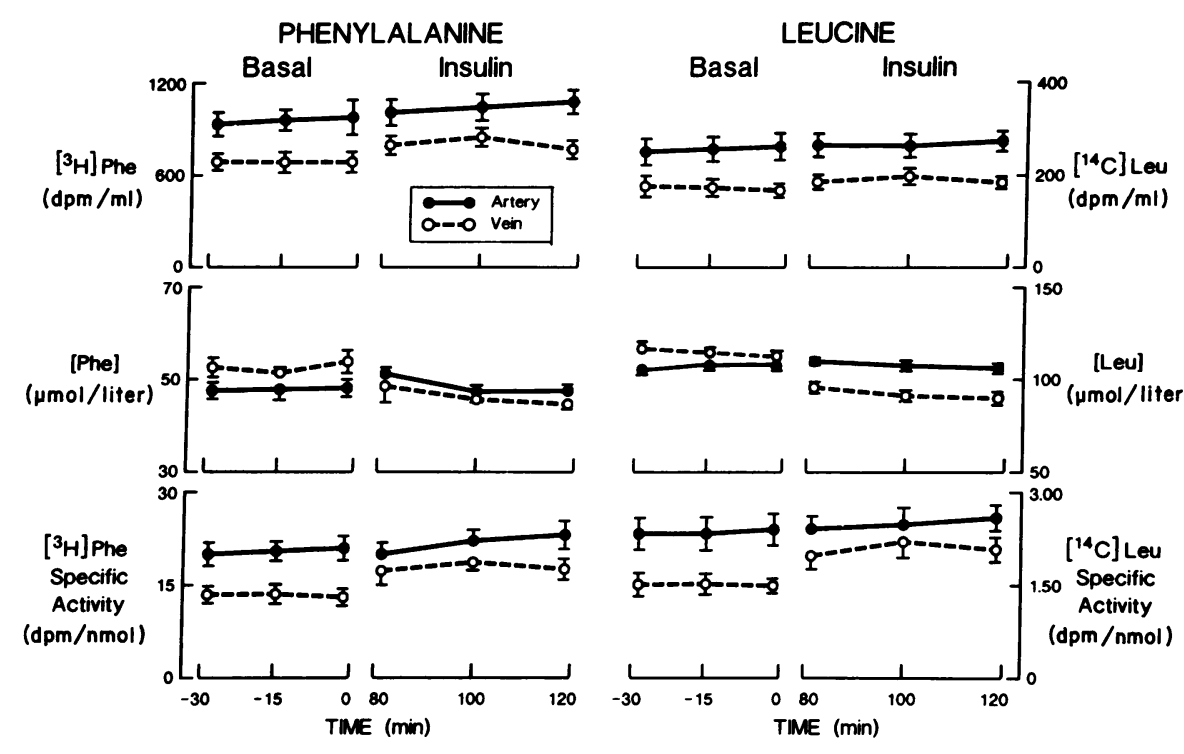

Figure 1. Arterial and venous radioactivity, concentration, and specific activity of phenylalanine and leucine at each sampling interval during the basal and insulin infusion periods. For each measurement the coefficient of variation from the mean plateau value in artery or vein for that period was $<5 \%$. with previous work suggesting that hyperinsulinemia may directly augment muscle blood flow (20). In keeping with the negligible change in systemic insulin levels, arterial concentrations of phenylalanine and leucine (Table I), as well as total acidic and neutral amino acids $(2,208 \pm 112 \mu \mathrm{mol} /$ liter, basal, vs. $2126 \pm 93$, insulin, $P=N S$ ), were not altered by the local insulin infusion. Similarly, no significant changes were observed in the whole body flux rates of circulating phenylalanine $(38 \pm 2 \mu \mathrm{mol} /$ min) and leucine (93 $\pm 6 \mu \mathrm{mol} / \mathrm{min})$ during local hyperinsulinemia ( $P=$ NS vs. basal).

During insulin infusion, forearm muscle balance of both phenylalanine and leucine reversed from a basal net output to a net uptake (to $9 \pm 3$ and $61 \pm 8 \mathrm{nmol} / \mathrm{min}$ per $100 \mathrm{ml}$, respectively, $P<0.005$ ) (Fig. 2). Despite the very marked increase in net uptake of these amino acids from blood, the tracer data demonstrate that for both phenylalanine and leucine the actual tissue disposal rates $\left(R_{d}\right)$ of circulating amino acid $(42 \pm 2$ and

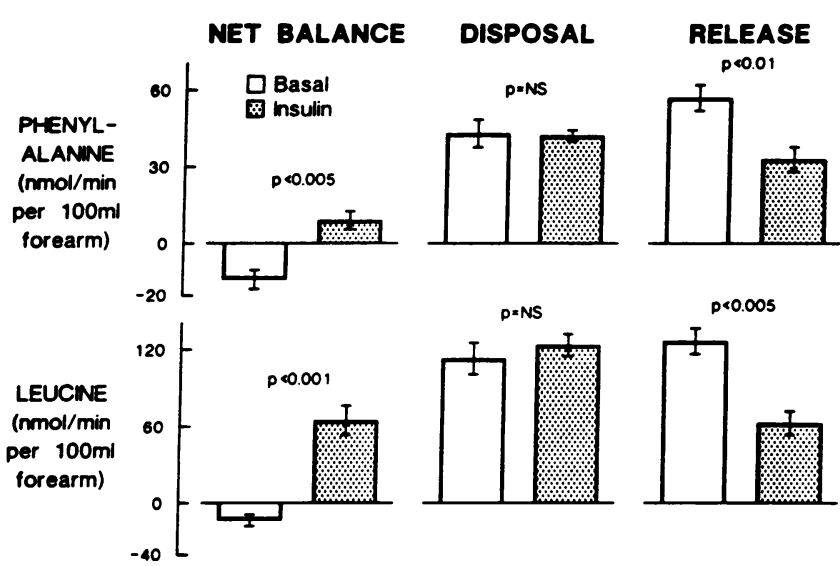

Figure 2. Exchange kinetics of phenylalanine and leucine across forearm muscle. The net balance of both amino acids (left) reversed from a net release in the postabsorptive state to a net uptake in response to physiologic hyperinsulinemia. Insulin had no measurable effect on tissue amino acid disposal $\left(R_{\mathrm{d}}\right)$ (middle), while tissue release of unlabeled amino acid $\left(R_{\mathrm{a}}\right)$ was markedly suppressed by insulin (right).
$124 \pm 9 \mathrm{nmol} / \mathrm{min}$ per $100 \mathrm{ml}$, respectively) were not significantly altered by insulin. Rather, the entire effect of insulin to promote a more positive net balance could be accounted for by a pronounced suppression of the release from forearm muscle $\left(R_{\mathrm{a}}\right)$ of unlabeled phenylalanine (by $42 \%$, to $33 \pm 5 \mathrm{nmol} / \mathrm{min}$ per 100 $\mathrm{ml}, P<0.01$ ) and leucine (by $50 \%$, to $63 \pm 9, P<0.005$ ).

\section{Discussion}

Our current understanding of the regulation of muscle protein metabolism in man has been limited by the lack of a suitable in vivo technique for monitoring rates of muscle protein turnover. Conventional tissue balance methods measure only the net exchange of amino acids across a muscle bed, but can provide no information about muscle protein turnover, or about the ongoing rates of tissue amino acid disposal and production that together determine the net tissue balance. The present study demonstrates how amino acid tracers can be used to resolve the net tissue balance measurement into its component $R_{\mathrm{d}}$ and $R_{\mathrm{a}}$. With the appropriate choice of amino acid tracer, these tissue amino acid kinetic measurements can in turn provide information about rates of muscle protein synthesis, breakdown, or both.

Phenylalanine, which is neither synthesized nor degraded in muscle, has been widely used as a tool to probe muscle protein physiology in vitro $(2,4,7,16)$. Because its only fates in muscle are incorporation into or release from protein, the measured net muscle balance of phenylalanine should, at steady state (i.e., when intracellular free phenylalanine is not changing), directly reflect the difference between the rates of muscle protein synthesis and breakdown. Thus, the net release of phenylalanine observed in the postabsorptive state signifies that rates of muscle protein breakdown exceed those of synthesis after an overnight fast. Insulin reversed this relationship, as evidenced by the net uptake of phenylalanine (Fig. 2), indicating the achievement of a net protein anabolic state in skeletal muscle.

Pozefsky et al. (10) have previously shown that local forearm hyperinsulinemia of even brief duration ( $26 \mathrm{~min}$ ) markedly diminishes the postabsorptive net release of amino acids, including 
leucine and phenylalanine, from forearm muscle. However, actual net uptake of amino acids was not observed in those studies (10). The more marked anabolic effect achieved in the present study at comparable insulin concentrations most likely reflects the longer duration of insulin infusion, suggesting that the anabolic action of insulin on muscle is not immediate, but may require up to 60-90 min for its full expression.

The information obtainable from conventional forearm balance measurements can be markedly enhanced by the simultaneous systemic infusion of amino acid tracers. The observed disappearance of an amino acid tracer across the forearm provides a measure of the quantity of amino acid which entered the tissue via the artery but did not exit via the vein. At steady state, i.e., when the free intracellular pool is not changing in size or specific activity, this measurement $\left(R_{d}\right)$ reflects the tissue disposal of circulating amino acid. This calculation is precisely analogous to the flux calculation routinely employed in whole body amino acid (e.g., leucine) turnover studies, where the total disappearance of infused tracer is presumed, at steady state, to reflect whole body tissue amino acid disposal. Although absolute verification of steady state conditions, for any amino acid kinetic technique, would in theory require direct measurements of tissue pools, in human studies steady state can be reasonably inferred when circulating amino acid kinetics are shown to be stable over time. In the present study, arterial specific activities of phenylalanine and leucine were stable over the 2.5 -h period of sampling, consistent with the achievement of steady state labeling of body free amino acid pools. Moreover, the existence of steady state conditions specifically in forearm muscle during both the basal and insulin-infused states is strongly supported by the constancy, over each 40-min observation period, of deep venous specific activity measurements, as shown in Fig. 1.

For phenylalanine, $R_{\mathrm{d}}$ provides a measure of muscle protein synthesis, the only route of disposal of phenylalanine entering via the artery but not exiting via the vein. Conversely, the production of new, unlabeled phenylalanine across the tissue $\left(R_{\mathrm{a}}\right)$ must reflect its release from the breakdown of tissue protein. For leucine, $\boldsymbol{R}_{\mathrm{d}}$ reflects not only its incorporation into protein, but also its tissue disposal via intracellular metabolism (transamination, oxidation). It should be noted that the observed ratio of leucine $R_{\mathrm{d}}$ to phenylalanine $R_{\mathrm{d}}$ in the present study averaged 2.6 to 2.9 in the postabsorptive and insulinized states, which is similar to the reported ratio of $\mathbf{2 . 4}$ for these amino acids in skeletal muscle protein (19). This observation suggests that in skeletal muscle, as in the whole body (19), incorporation into protein accounts for the bulk of total leucine turnover. Thus, while the kinetics of forearm muscle leucine exchange cannot be regarded as a pure measure of tissue protein turnover, any major change in rates of tissue protein synthesis or breakdown, as reflected by phenylalanine $\boldsymbol{R}_{\mathrm{d}}$ and $\boldsymbol{R}_{\mathrm{a}}$, should generally be reflected, at least in a directional sense, by parallel changes in leucine kinetics.

The present study demonstrates the effect of insulin on forearm muscle phenylalanine and leucine kinetics. As shown in Fig. 2, the entire effect of insulin to promote a positive muscle balance of these amino acids could be accounted for by marked inhibition of cold amino acid release into venous blood. Forearm muscle disposal of both phenylalanine and leucine showed no significant change from baseline. These observations using two independent amino acids suggest that in normal man hyperinsulinemia of this magnitude and duration may not substantially stimulate protein synthesis above basal rates. Rather, the potent net anabolic action of insulin on muscle in this setting appears to be mediated primarily by a marked reduction in the rate of protein breakdown.

Inferences about tissue protein physiology based on circulating amino acid kinetic measurements must always be approached with caution. A number of methodologic assumptions and limitations must be explicitly acknowledged. Key among these, of course, is the assumption that phenylalanine is not metabolized in skeletal muscle, a view that is strongly supported by in vitro animal studies $(2,15-17)$, but for which the evidence in man remains largely indirect. An assumption implicit in our method, as in all in vivo amino acid turnover techniques, is that there is no label recycling, i.e., that tracer incorporated into protein is not released back into the free amino acid pool (thereby lowering flux estimates) during the period of observation. In whole body turnover studies, such recycling has been shown to become quantitatively significant during prolonged (e.g., $18 \mathrm{~h}$ ) amino acid tracer infusions in man, presumably reflecting release of tracer from short-lived body proteins (21). In the present study, given the short total duration of tracer infusion $(4 \mathrm{~h})$, the very brief $(2 \mathrm{~h})$ period that separated the basal and experimental measurements, and the relatively slow turnover of muscle as compared with other body proteins (19), the contribution of label recycling to our comparative forearm measurements should be negligible. Empirical support for this view is provided by the stability of the whole body flux estimates (reflecting muscle as well as other, more rapidly turning over proteins) measured over this same time period. Finally, the dependence of all tissue balance calculations on the measurement of blood flow should be emphasized, as the difficulties intrinsic to this measurement, such as the potential for incomplete mixing of dye (13), will obviously limit the ultimate accuracy of tissue kinetic estimates. Such considerations underscore some of the quantitative limitations of the present method.

Perhaps the most important uncertainty involved in extrapolating circulating amino acid kinetics to tissue protein turnover arises from our inability to directly measure the amino acid specific activity in the actual precursor pool for protein synthesis, namely, aminoacyl-tRNA. To the extent that the specific activity of phenylalanyl-tRNA may be lower than that of arterial phenylalanine (due to dilution by internally recycled phenylalanine), the present calculations, based on blood amino acid kinetics, must be regarded as minimum estimates of the rate of tissue protein turnover. This uncertainty regarding precursor pool specific activity is not unique to the present method but is shared by all amino acid turnover techniques used to assess body protein metabolism in man (19). In the context of whole body leucine turnover studies, one approach to this problem has involved the measurement of circulating alpha-ketoisocaproate (KIC) specific activity as an index of mixed intracellular leucine specific activity (22). Although such an approach does not provide a direct index of the true precursor pool for protein synthesis (aminoacyl-tRNA specific activity is generally higher than that of the mixed intracellular pool [23-26]), it does provide a valuable means for monitoring changes in intracellular tracer dilution occurring in the course of an experiment. In the context of the present method, an analogous approach takes advantage of the fact that the specific activity of venous phenylalanine $\left(S A_{\mathrm{v}}\right)$, having been diluted by phenylalanine released from the intracellular pool, should be closer to the mixed intracellular specific activity than are the arterial measurements, and changes in intracellular phe- 
nylalanine dilution should be reflected by changes in $S A_{\mathrm{v}}$. Thus, the increase in $S A_{v}$ observed during insulin infusion (Fig. 1, Table I) is consistent with a rise in intracellular specific activity due to inhibition of protein breakdown by insulin. Calculating $R_{\mathrm{a}}$ and $R_{\mathrm{d}}$ using $S A_{\mathrm{v}}$ rather than $S A_{\mathrm{a}}$ as the reference pool then provides an alternative means for estimating phenylalanine kinetics which should be responsive to changes in intracellular dilution. With this change Eq. 4 becomes $R_{\mathrm{a}}=F \times[A] \times\left(S A_{\mathrm{a}}\right)$ $\left.S A_{\mathrm{v}}-1\right)$, which is analogous to the equation used by others $(2$, 16) to assess protein degradation in isolated perfused muscle preparations. Applying this approach to the present data yields higher absolute estimates for rates of phenylalanine release from protein $(82 \pm 9 \mathrm{nmol} / \mathrm{min}$ per $100 \mathrm{ml}$, basal), but a virtually identical fractional suppression (by $46 \%$ ) in response to insulin (to $44 \pm 7, P<0.02$ ). Phenylalanine incorporation into protein estimated in this fashion $\left(F \times\left[\mathrm{dpm} / \mathrm{ml}_{\mathrm{a}}-\mathrm{dpm} / \mathrm{ml}_{\mathrm{v}}\right] / S A_{\mathrm{v}}\right)$ again showed no significant change, and if anything a slight fall, in response to insulin $(68 \pm 9$ to $53 \pm 4 \mathrm{nmol} / \mathrm{min}$ per $100 \mathrm{ml}, P$ $=\mathrm{NS})$. Although it remains unclear whether $S A_{\mathrm{a}}$ or $S A_{\mathrm{v}}$ provides the better absolute estimate of phenylalanyl-tRNA specific activity, application of either model to the present observations leads to the same conclusion, namely, that hyperinsulinemia suppressed tissue proteolysis but did not measurably stimulate protein synthesis.

These results appear to be at variance with a wealth of in vitro data demonstrating that insulin not only inhibits protein degradation (1-6), but also stimulates protein synthesis in skeletal muscle (1-9). While we cannot definitively exclude a small increase in synthesis in response to insulin (type II error), our results do provide evidence that the major anabolic effect of hyperinsulinemia in vivo is exerted at the level of protein degradation. This in vivo response appears to differ from that of muscle studied in vitro, where synthesis, rather than degradation, is generally found to be the more insulin-sensitive process $(2,3,6)$.

Direct extrapolation of the in vitro effects of insulin to the in vivo setting of physiologic hyperinsulinemia must be undertaken with caution. In fact, the discrepancy between the present study results and those obtained in vitro may actually be more apparent than real. Investigators studying both perfused (2) and isolated (8) muscle preparations have noted little or no effect of insulin to stimulate protein synthesis early in the incubation period, when synthetic rates are highest and presumably closest to those present in vivo. It is only during subsequent hours, when synthesis rates decline in muscles maintained without insulin, that a rapid stimulatory effect of added insulin is readily demonstrable $(2,8)$. Interestingly, muscles from insulin-deficient diabetic animals, which exhibit depressed rates of protein synthesis in vitro, do respond to insulin during the initial period of perfusion $(4,7)$. In keeping with these observations, in vivo studies have readily shown an impairment in muscle protein synthesis in diabetic animals, which is at least partially reversible with insulin (27-30), while stimulation of synthesis by insulin in nondiabetic animals has proved far more difficult to demonstrate (28). These considerations, coupled with the present study results, raise the possibility that the stimulatory effect of insulin on protein synthesis may be manifest in vivo at normal postabsorptive insulin concentrations. Suppression of degradation, in contrast, may require higher insulin concentrations for its full expression in vivo, as is the case in vitro (2). Such a formulation, although speculative, could largely reconcile the present study results with the reported effects of insulin on muscles in vitro.

The present findings in forearm tissues are entirely consistent with the reported effects of insulin on whole body protein turnover in normal man. Using the $\mathrm{L}-\left[1-{ }^{13} \mathrm{C}\right]$ leucine turnover technique in combination with the euglycemic insulin clamp, Fukagawa et al. (31) have shown an inhibition of total leucine flux (an index of body proteolysis) but no stimulation of nonoxidative leucine disposal (an index of protein synthesis) in response to physiologic or pharmacologic hyperinsulinemia. Others have reported similar findings $(32,33)$. Since skeletal muscle constitutes the major reservoir of body protein, it is unlikely that a pronounced effect of insulin on muscle protein synthesis was present but not reflected in the whole body measurement. Complicating the interpretation of these whole body studies, however, are the many alterations in circulating substrate concentrations caused by systemic insulin administration (e.g., decreased amino acids, free fatty acids); hypoaminoacidemia, for example, may itself restrain rates of tissue protein synthesis. The forearm perfusion technique, in contrast, permits insulin levels to be raised locally without altering the perfusing concentrations of amino acids and other substrates; because the mass of the forearm is so small relative to total body mass (e.g., the contribution of one forearm to total body leucine and phenylalanine $R_{\mathrm{a}}$ is $<2 \%$ ), even marked changes in forearm amino acid metabolism have little effect on arterial amino acid concentrations. Thus, our finding that insulin markedly inhibited muscle proteolysis without measurably stimulating protein synthesis cannot be attributed to insulin-induced changes in the circulating supply of amino acid precursors or energy substrates.

Previous attempts to quantitate muscle protein synthesis in man have employed muscle biopsies to directly measure label incorporation into protein during infusion of stable isotope-labeled amino acids $(34,35)$. Using $\left[{ }^{15} \mathrm{~N}\right]$ lysine, Halliday and McKeran (34) estimated a fractional synthetic rate of $1.5 \pm 0.3 \%$ per $\mathbf{d}$ for myofibrillar protein (the bulk of muscle protein). Rennie et al. (35), using $\mathrm{L}-\left[1-{ }^{13} \mathrm{C}\right]$ leucine, reported a daily fractional synthetic rate of $2.4 \pm 1.0 \%$ for total muscle protein. The present method, in which phenylalanine incorporation is estimated indirectly, can be compared with these earlier techniques by expressing the kinetic results per unit mass of forearm muscle. Since skeletal muscle receives $\sim 85 \%$ of the forearm blood flow and occupies $60 \%$ of forearm volume (11), it can be estimated from our data that phenylalanine incorporation in the postabsorptive state averaged $60 \pm 7 \mathrm{nmol} / \mathrm{min}$ per $100 \mathrm{~g}$ of forearm muscle. If one assumes that skeletal muscle protein contains $\mathbf{4 5}$ $\mu \mathrm{mol}$ of phenylalanine residues per $\mathrm{g}$ of wet muscle weight (19), our observations yield a fractional synthetic rate of $1.9 \pm 0.2 \%$ per $\mathbf{d}$ for human forearm muscle under postabsorptive conditions. This result, obtained from arterial and venous blood measurements alone, agrees well with the earlier estimates using tissue biopsies. In addition to its obvious advantage of not requiring tissue samples, the present method is unique in enabling the simultaneous estimation of muscle protein breakdown $(2.5 \pm 0.2 \%$ per $\mathrm{d}$ in the postabsorptive state), and in permitting the study, with repeated measurements over time, of the effects of physiologic interventions on muscle protein turnover.

In summary, the results of the present study provide strong evidence that inhibition of protein breakdown, rather than stimulation of synthesis, is the major mechanism whereby acute physiologic elevations in insulin promote net muscle protein 
anabolism in normal man. The measurement of forearm phenylalanine kinetics provides a unique, nondestructive in vivo technique for assessing rates of protein synthesis and breakdown in human skeletal muscle.

\section{Acknowledgments}

This work was supported by the Yale General Clinical Research Center (RR-125) and by National Institutes of Health grant AM-34241. Dr. Gelfand is the recipient of a Clinical Associate Physician Award, Yale General Clinical Research Center.

\section{References}

1. Fulks, R. M., J. B. Li, and A. L. Goldberg. 1975. Effects of insulin, glucose, and amino acids on protein turnover in rat diaphragm. J. Biol. Chem. 250:290-298.

2. Jefferson, L. S., J. B. Li, and S. R. Rannels. 1977. Regulation by insulin of amino acid release and protein turnover in the perfused rat hemicorpus. J. Biol. Chem. 252:1476-1483.

3. Frayn, K. N., and P. F. Maycock. 1979. Regulation of protein metabolism by a physiological concentration of insulin in mouse soleus and extensor digitorum longus muscles. Biochem. J. 1984:323-330.

4. Jefferson, L. S., D. E. Rannels, B. L. Munger, and H. E. Morgan. 1974. Insulin in the regulation of protein turnover in heart and skeletal muscle. Fed. Proc. 33:1098-1 104.

5. Li, J. B., J. E. Higgins, and L. S. Jefferson. 1979. Changes in protein turnover in skeletal muscle in response to fasting. Am. J. Physiol. 236:E222-E228.

6. Lundholm, K., S. Edstrom, L. Ekman, I. Karlberg, P. Walker, and T. Schersten. 1981. Protein degradation in human skeletal muscle tissue: the effect of insulin, leucine, amino acids, and ions. Clin. Sci. 60: 319-326.

7. Jefferson, L. S. 1980. Role of insulin in the regulation of protein synthesis. Diabetes. 29:487-496.

8. Stirewalt, W. S., R. B. Low, and J. M. Slaiby. 1985. Insulin sensitivity and responsiveness of epitrochlearis and soleus muscles from fed and starved rats. Biochem. J. 227:355-362.

9. Jefferson, L. S., J. O. Koehler, and H. E. Morgan. 1972. Effect of insulin on protein synthesis in skeletal muscle of an isolated perfused preparation of rat hemicorpus. Proc. Natl. Acad. Sci. USA. 69:816-820.

10. Pozefsky, T., P. Felig, J. D. Tobin, J. S. Soeldner, and G. F. Cahill, Jr. 1969. Amino acid balance across tissues of the forearm in postabsorptive man. Effects of insulin at two dose levels. J. Clin. Invest. 48:2273-2282.

11. Andres, R., G. Cader, and K. L. Zierler. 1956. The quantitatively minor role of carbohydrate in oxidative metabolism by skeletal muscle in intact man in the basal state. Measurements of oxygen and glucose uptake and carbon dioxide and lactate production in the forearm. $J$. Clin. Invest. 35:671-682.

12. Coles, D. R., K. E. Cooper, R. F. Mottram, and J. V. Occleshaw. 1958. The source of blood samples withdrawn from deep forearm veins via catheters passed upstream from the median cubital vein. J. Physiol. 142:323-328.

13. Andres, R., K. L. Zierler, H. M. Anderson, W. N. Stainsby, G. Cader, A. S. Ghrayyib, and J. L. Lilienthal, Jr. 1954. Measurement of blood flow and volume in the forearm of man; with notes on the theory of indicator-dilution and on production of turbulence, hemolysis, and vasodilatation by intra-vascular injection. J. Clin. Invest. 33:482-504.

14. Morgan, C. R., and A. Lazarow. 1963. Immunoassay of insulin: two antibody system. Diabetes. 12:115-122.

15. Goldberg, A. L., and R. Odessey. 1972. Oxidation of amino acids by diaphragms from fed and fasted rats. Am. J. Physiol. 223:1384-1391.

16. Rannels, D. E., J. B. Li, H. E. Morgan, and L. S. Jefferson. 1975. Evaluation of hormone effects on protein turnover in isolated perfused organs. Methods Enzymol. 37:238-250.

17. Williams, I. H., P. H. Sugden, and H. E. Morgan. 1981. Use of aromatic amino acids as monitors of protein turnover. Am. J. Physiol. 249:E677-E681.

18. Clarke, J. T. R., and D. M. Bier. 1982. The conversion of phenylalanine to tyrosine in man. Direct measurement by continuous intravenous tracer infusions of $\mathrm{L}-\left[\mathrm{ring}^{2}{ }^{2} \mathrm{H}_{5}\right]$ phenylalanine and $\mathrm{L}-[1-$ ${ }^{13} \mathrm{C}$ tyrosine in the postabsorptive state. Metab. Clin. Exp. 31:999-1005.

19. Waterlow, J. C., P. J. Garlick, and D. J. Millward. 1978. Protein Turnover in Mammalian Tissues and in the Whole Body. Elsevier/North Holland Publishing Co., New York. 804.

20. Liang, C. S., J. U. Doherty, R. Faillace, K. Maekawa, S. Arnold, H. Gavras, and W. B. Hood, Jr. 1982. Insulin infusion in conscious dogs: Effects on systemic and coronary hemodynamics, regional blood flows, and plasma catecholamines. J. Clin. Invest. 69:1321-1336.

21. Tsalikian, E., C. Howard, J. E. Gerich, and M. W. Haymond. 1984. Increased leucine flux in short-term fasted human subjects: evidence for increased proteolysis. Am. J. Physiol. 247:E323-E327.

22. Matthews, D. E., H. P. Schwarz, R. D. Yang, K. J. Motil, V. R. Young, and D. M. Bier. 1982. Relationship of plasma leucine and alphaketoisocaproate during $\mathrm{L}-[1-13 \mathrm{C}]$ leucine infusion in man: A method for measuring human intracellular leucine tracer enrichment. Metab. Clin. Exp. 31:1105-1112.

23. Rannels, D. E., S. A. Wartell, and C. A. Watkins. 1982. The measurement of protein synthesis in biological systems. Life Sci. 30: 1679-1690.

24. Morgan, H. E., D. E. Rannels, and E. E. McKee. 1979. Protein metabolism of the heart. In Handbook of Physiology: The Cardiovascular System. American Physiological Society, Bethesda, MD. 845-871.

25. Martin, A. F., M. Rabinowitz, R. Blough, G. Prior, and R. Zak. 1977. Measurements of half-life of rat cardiac myosin heavy chain with leucyl-tRNA used as precursor pool. J. Biol. Chem. 252:3422-3429.

26. Airhart, J., J. A. Arnold, W. S. Stirewalt, and R. B. Low. 1982. Insulin stimulation of protein synthesis in cultured skeletal and cardiac muscle cells. Am. J. Physiol. 243:C81-C86.

27. Forker, L. L., I. L. Chaikoff, C. Entenman, and H. Tarver. 1951. Formation of muscle protein in diabetic dogs studied with ${ }^{35} \mathrm{~S}$-methionine. J. Biol. Chem. 188:37-48.

28. Pain, V. M., and P. J. Garlick. 1974. Effect of streptozotocin diabetes and insulin treatment on the rate of protein synthesis in tissues of the rat in vivo. J. Biol. Chem. 249:4510-4514.

29. Odedra, B. R., S. D. Sreedevi, and D. J. Millward. 1982. Muscle protein synthesis in the streptozotocin-diabetic rat: a possible role of corticosterone in the insensitivity to insulin infusions in vivo. Biochem. J. 202:363-368.

30. Sloan, G. M., J. A. Norton, and M. F. Brennan. 1980. Influence of diabetes mellitus and insulin treatment on protein turnover in the rat. J. Surg. Res. 28:442-448.

31. Fukagawa, N. K., K. L. Minaker, J. W. Rowe, M. N. Goodman, D. E. Matthews, D. M. Bier, and V. R. Young. 1985. Insulin-mediated reduction of whole body protein breakdown. Dose-response effects on leucine metabolism in postabsorptive man. J. Clin. Invest. 76:23062311.

32. Tessari, P., R. Nosadini, R. Trevisan, S. V. De Kreutzenberg, S. Inchiostro, E. Duner, G. Biolo, M. C. Marescotti, A. Tiengo, and G. Crepaldi. 1986. Defective suppression by insulin of leucine-carbon appearance and oxidation in type 1, insulin-dependent diabetes mellitus. J. Clin. Invest. 77:1797-1804.

33. Tessari, P., R. Trevisan, S. Inchiostro, G. Bioli, R. Nosadini, S. V. De Kreutzenberg, E. Duner, A. Tiengo, and G. Crepaldi. 1986. Dose-response curves of effects of insulin on leucine kinetics in humans. Am. J. Physiol. 251:E334-E342.

34. Halliday, D., and R. O. McKeran. 1975. Measurement of muscle protein synthetic rate from serial muscle biopsies and total body protein turnover in man by continuous intravenous infusion of $L-\left[\alpha-{ }^{15} \mathrm{~N}\right]$ lysine. Clin. Sci. Mol. Med. 49:581-590.

35. Rennie, M. J., R. H. T. Edwards, D. Halliday, D. E. Matthews, S. L. Wolman, and D. J. Millward. 1982. Muscle protein synthesis measured by stable isotope techniques in man: the effects of feeding and fasting. Clin. Sci. 63:519-523. 